\title{
Intradural Tophaceous Gout of the Cavernous Sinus and Spine: Case Report and Review of Literature
}

Reinard KA1, Felicella MM1', Zakaria HM¹ and Rock JP1,2

${ }^{1}$ Departments of Neurosurgery, Henry Ford Hospital, Detroit, MI, USA

${ }^{2}$ Departments of Neuropathology, Henry Ford Hospital, Detroit, MI, USA

\begin{abstract}
Background: Purine-rich diets and improper metabolism of uric acid result in deposition of monosodium urate crystals in multiple organs throughout the body. Gout is typically characterized by recurrent attacks of inflammatory arthritis; however, deposition of uric acid crystals in the spinal canal may result in debilitating back pain, neural compression, and progressive myelopathy. While extradural gout is a widely reported source of spinal cord compression, we present a novel case of an individual with intradural tophaceous gout in the cranial and spinal cavities.
\end{abstract}

Case history: A 61-year-old African-American male presented with diplopia, masticatory difficulty, and facial pain Serial imaging revealed an enlarging, heterogeneously enhancing mass in the left cavernous sinus with extension into the superior orbital fissure and foramen ovale, raising suspicion for a meningioma. Successful surgical resection of the cavernous lesion was undertaken to eliminate the risk of permanent ophthalmoplegia and blindness. The pathological findings were felt to be compatible with chondroma. Nine years later, after stable yearly imaging follow-up of the cranial lesion, the patient presented with progressive myelopathy. Imaging of the spine revealed enhancing, intradural lesions suggestive of calcified meningiomas. Surgical resection was undertaken to preserve motor function. Histopathologic diagnosis after spinal decompression was tophaceous gout. Retrospective review of the cranial pathology indicated that this lesion, too, was consistent with tophaceous gout.

Conclusion: The pathophysiology of spinal tophaceous gout is well known and extradural lesions are not uncommon. However, multifocal intradural tophi involving intracranial and intraspinal compartments have not been previously reported. This case represents the first reported case of both intracranial and intraspinal intradural tophaceous gout causing neurological deficits.

\section{Introduction}

With a worldwide incidence of $0.4 \%$ [1], gout is a prevalent metabolic disorder that results from the inappropriate metabolism of uric acid and deposition of monosodium urate crystals in tissues [2]. While gout is typically associated with an inflammatory arthritis of the peripheral joints, gouty involvement of the axial spine is a well-known and underreported source of back pain, radiculopathy, myelopathy, and even paraplegia [1-4]. Since Koskoff et al. described the first case of extradural gout causing paraplegia [5], the radiographic prevalence of axial spine gout has been estimated to be between $14 \%$ and $35 \%$ in patients with poorly controlled hyperuricemia [2,6-8].

Though spinal gout can involve any portion of the spine, the preponderance of lesions occur in the lumbar spine $[1,2,4,7,8]$, and more than $80 \%$ of patients with gout may harbor multiple gouty lesions $[2,4]$. The clinical diagnosis of spinal gout remains a challenge because the common presenting findings such as fever, leukocytosis, and elevated systemic inflammatory markers such as sedimentation rate more commonly suggest infection [9-12]. Fortunately, characteristic findings on magnetic resonance imaging (MRI) [13,14], computed tomography (CT) $[15,16]$, or ultrasound [17] serve as useful adjuncts for proper diagnosis of spinal gout. Successful medical and surgical management of spinal gout has been previously described in the literature [1,4,18-20].

Whereas tophaceous gout of the calvarium [21], infratemporal fossa [22], middle ear [22,23], and cervicomedullary junction with involvement of lower cranial nerves [24] have been reported in the past, to our knowledge, intradural tophaceous gout has not been described. We present the first case of an individual with gouty tophi involving the cavernous sinus and the intradural spinal compartment.

\section{Case Presentation}

A 61-year-old, African-American male with stage 1 chronic kidney disease, hypertension, and gout (uric acid levels $<7.0 \mathrm{mg} / \mathrm{dL}$ maintained on allopurinol) presented to the outpatient neurosurgery clinic with headaches, diplopia, masticatory difficulty, and neuralgia along the third division of the left trigeminal nerve. On examination, he was found to have left abducens palsy, weakness of the left masseter, and trismus. MRI of the brain revealed a large lesion in the lateral wall of the left cavernous sinus and Meckel's cave as well as an incidental lipoma. The lesion appeared hypointense on T1- and T2-weighted images and demonstrated contrast enhancement. The soft tissue mass extended into the infratemporal and pterygopalatine fossae via the foramina ovale and rotundum, respectively (Figure 1A-1C). Marked denervation atrophy of the masticator and pterygoid muscles was also noted. Follow-up MRI of the brain demonstrated further extension of the mass into the left superior orbital fissure. Surgical resection via a trans-Sylvian corridor was undertaken to prevent permanent ophthalmoplegia and blindness. Intra-operatively the cavernous sinus dura appeared thickened but was devoid of excessive vascularity. On gross examination, the lesion was well circumscribed and had a pale, bluish-grey appearance typical of cartilage. The patient recovered well from his operation and on 6-week follow-up examination had no visual acuity deficits or abducens palsy.

*Corresponding author: Dr. Jack P. Rock, Departments of Neuropathology, Henry Ford Hospital, Detroit, MI 48202, USA, Tel: 313-916-1094; E-mail: jrock1@hfhs.org

Received April 10, 2015; Accepted May 20, 2015; Published May 24, 2015

Citation: Reinard KA, Felicella MM, Zakaria HM, Rock P (2015) Intradural Tophaceous Gout of the Cavernous Sinus and Spine: Case Report and Review of Literature. J Neurol Disord 3: 234. doi: 10.4172/2329-6895.1000234

Copyright: (c) 2015 Reinard KA, et al. This is an open-access article distributed under the terms of the Creative Commons Attribution License, which permits unrestricted use, distribution, and reproduction in any medium, provided the original author and source are credited. 
Citation: Reinard KA, Felicella MM, Zakaria HM, Rock P (2015) Intradural Tophaceous Gout of the Cavernous Sinus and Spine: Case Report and Review of Literature. J Neurol Disord 3: 234. doi: 10.4172/2329-6895.1000234
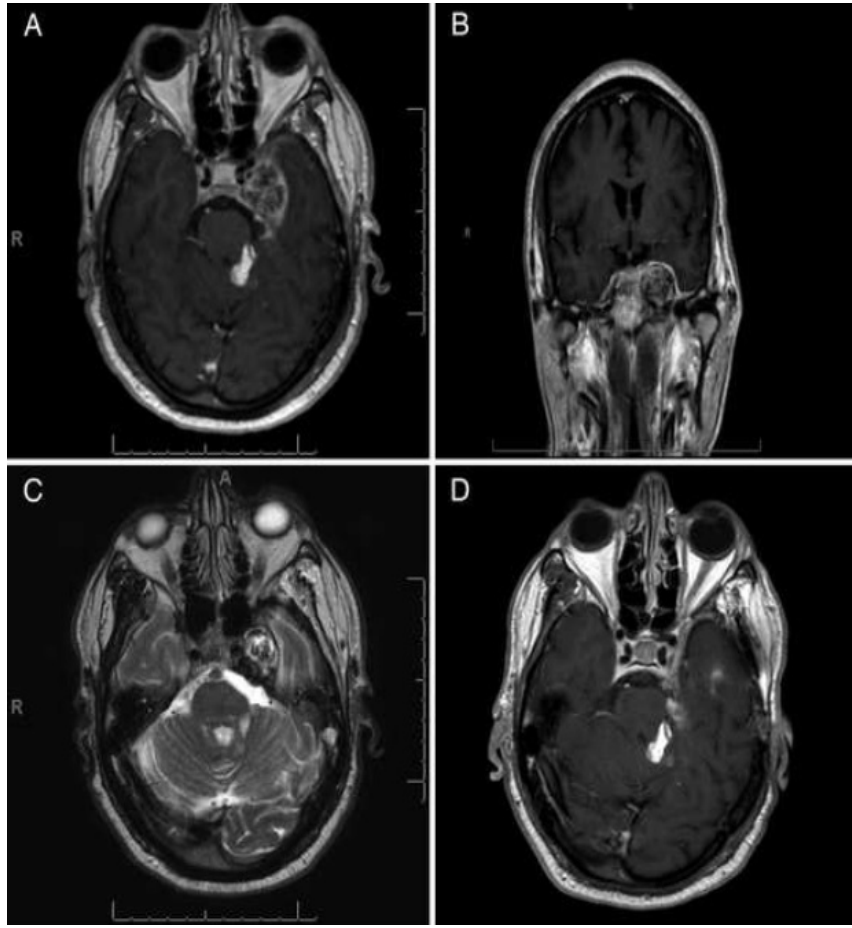

Figure 1: (A) Preoperative contrasted, axial MRI reveals an enhancing lesion in the wall of the left cavernous sinus and in proximity to the left Meckel's cave. (B) Preoperative contrasted, sagittal MRI reveals extension of this soft tissue mass into the pterygopalatine and infratemporal fossa. (C) Preoperative T2-Weighted (T2W), axial MRI reveals areas of hypointensity suggestive of heavy calcium deposition. (D) Postoperative contrasted, axial MRI 9 years after the craniotomy reveals stable contrast enhancement along the wall of the left cavernous sinus and tentorium as well as a stable lipoma.

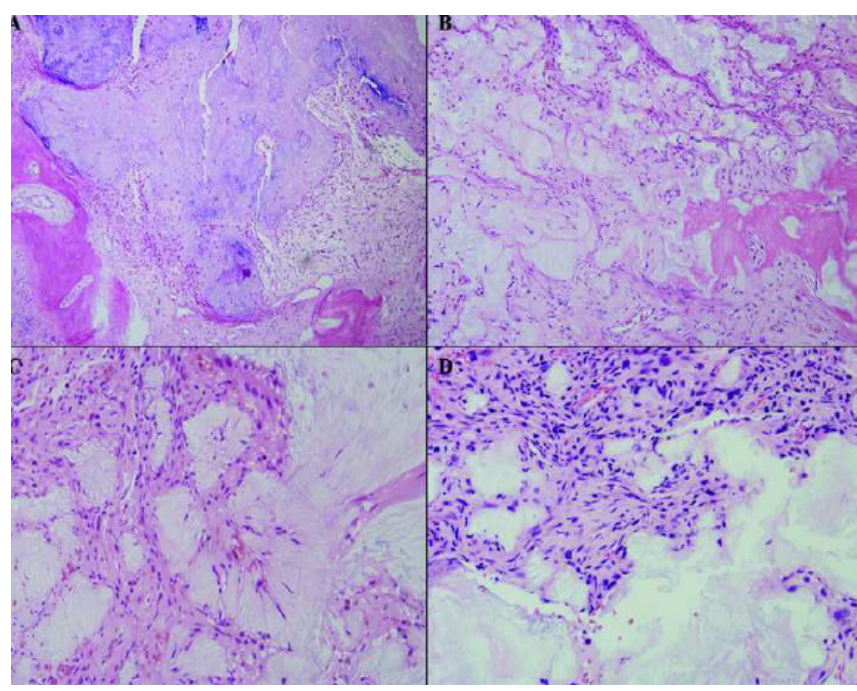

Figure 2: (A) Tissue section of the intracranial lesion showing abundant chondroosseous tissue (H\&E, 200x); (B) Chalky white fibrillary material is abundant in the specimen (H\&E, 200x). (C) Higher power images of fibrillary material demonstrates the small slit-like spaces previously occupied by urate crystals (H\&E, 400x); (D) Histiocytic reaction adjacent to the material (H\&E, 400x).

Histopathologic examination of the cranial lesion revealed abundant chondro-osseous tissue with associated fibrillary material containing slit-like spaces and a histiocytic infiltrate with occasional giant cells (Figure 2). At the time, the diagnosis was felt to be consistent with a chondroma, due to the extensive chondroid material present.
Yearly imaging follow-up revealed stable residual enhancement along the left cavernous sinus (Figure 1D).

Nine years after his craniotomy, the patient returned to the neurosurgery clinic with symptoms of chronic constipation, imbalance, and left lower extremity weakness. On neurological examination, he exhibited proximal left lower extremity strength of $4 / 5$ on the Medical Research Council (MRC) scale [25]. Muscle bulk and tone were within normal limits as were his lower extremity sensation and proprioception. The patient's reflexes were exaggerated without pathologic spread and he exhibited a myelopathic gait. CT of the spine revealed prominent flocculent and dense calcifications within the spinal canal in the lower thoracic and lumbar regions. The nonspecific appearance broadened the differential diagnosis to include arachnoiditis ossificans, inflammatory ossifying pseudotumor, and calcified amyloid deposits in addition to schwannoma and meningioma (Figure 3A). MRI of the spine revealed multiple, heavily calcified (T2-hypointense) lesions within the intradural, extramedullary compartment of the lower thoracic spine with surrounding vasogenic edema. The lesions demonstrated heterogeneous contrast enhancement with an associated dural tail (Figure 3B-3D). MRI of the brain was negative for acute stroke. Laboratory evaluation revealed normal uric acid levels $(7.0 \mathrm{mg} / \mathrm{dL})$, stable stage 1 kidney disease, elevated sedimentation rate $(28 \mathrm{~mm} / \mathrm{Hr})$, mildly elevated C-reactive protein $(1 \mathrm{mg} / \mathrm{dL})$, and normal leukocyte count $(10 \mathrm{~K} / \mathrm{uL})$.

Given the progressive myelopathy, surgical resection was undertaken through a decompressive laminectomy and midline durotomy under continuous electrophysiological monitoring. Immediately after the laminectomy was performed and prior to durotomy, monitoring indicated an acute and significant change with bilateral loss of the somatosensory evoked potential (SSEP) recordings. Because no hypotension was noted, it was elected to proceed with exploration and lesion removal. After dural opening, the mass appeared solid yellowish-white with a granular texture and was densely adherent to the surrounding dura and spinal cord pia. The lesion was carefully
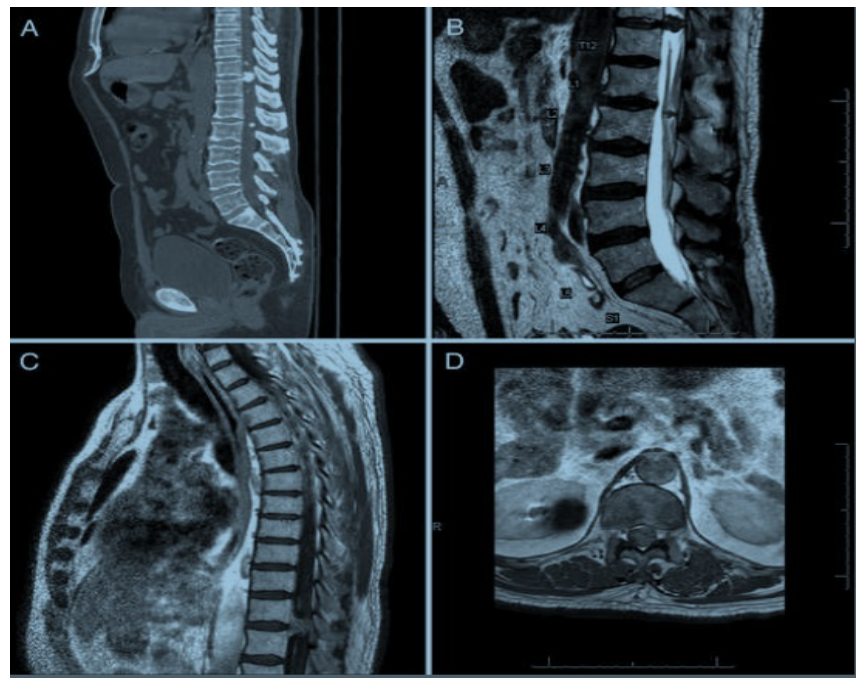

Figure 3: (A)Preoperative CT of the spine demonstrates nonspecific flocculent and dense calcification within the spinal canal without any associated bony changes. (B) Preoperative sagittal, T2W MRI of the spine reveals multiple hypointense, intradural extramedullary lesions at the thoracic-lumbar junction with vasogenic edema. (C and D) Contrasted sagittal and axial MRI of the lumbar spine demonstrates an enhancing intraspinal lesion with a dural trail that nearly occupies the entire spinal canal and causes significant mass effect on the spinal cord matter. 
dissected from the spinal cord using standard microsurgical techniques. After surgery, the patient experienced lower extremity paresis, worse on the left $(2 / 5)$ than the right $(3 / 5)$, which was persistent at the 6-week follow-up visit. It was felt at the time that the decompression afforded by the laminectomy, done entirely with drilling and no use of rongeurs, may have been sufficient to allow the spinal cord to become displaced by the lesion. The patient is scheduled to undergo a postoperative spinal MRI in 3 months.

Pathologic examination of the intraspinal lesion showed essentially identical morphologic features as the prior intracranial specimen (Figure 4A). There was a prominent histiocytic reaction surrounding the fibrillary material, within which were empty slit-like spaces where the urate crystals had dissolved out during formalin fixation (Figure 4B). There was extensive chondroid and osseous metaplasia, as was seen in the intracranial lesion, which may occur in chronic gouty tophi. The differential diagnosis included both tophaceous gout with an extensive reactive chondro-osseous metaplasia and a calcifying pseudoneoplasm of the neuraxis. No crystals could be found on polarization of the hematoxylin and eosin (H\&E) sections. However, given the high suspicion for gout based on the histologic features, $7-\mu \mathrm{m}$-thick unstained sections were cut from the tissue blocks and examined under polarized light. These unstained sections demonstrated innumerable needle shaped crystals, which had the typical strong negative birefringence of uric acid crystals under polarized light (Figure 4C and 4D). These findings confirmed the diagnosis of tophaceous gout.

The original diagnosis of the intracranial lesion as chondroma was based on the presence of large fragments of chondroid material. Degenerating cartilaginous tissue may have a fibrillary appearance and the fibrillar material was interpreted as a degenerative change in the intracranial specimen. The spinal lesion showed an abundance of the fibrillar material with cleft-like spaces and a more prominent histiocytic reaction, giving a clue to the diagnosis of a gouty tophus. Chronic tophaceous gout can cause a marked reactive metaplasia, with formation of metaplastic cartilage and bone. If extensive, this reactive change may be mistaken for a benign chondroid or osseous neoplasm, as occurred in this case.

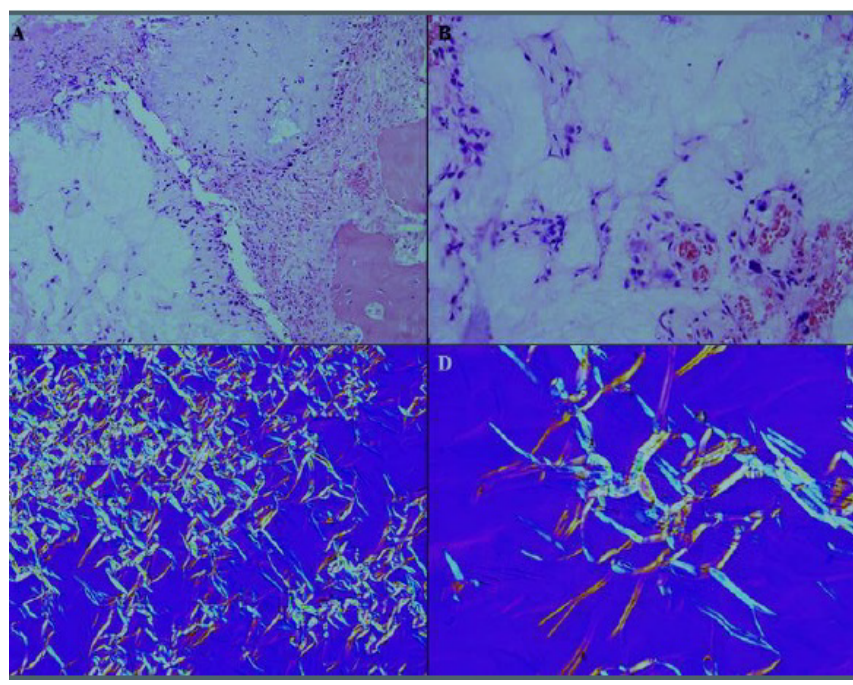

Figure 4: (A) Tissue section of thoracic intradural extramedullary lesion with chondro-osseous metaplasia, morphologically similar to the intracranial lesion from Figure 1 (H\&E, 200x); (B) Chalky fibrillary material with slitlike spaces and histiocytic reaction with rare giant cell (H\&E, 400x); (C and D) Needle shaped crystals showing strong negative birefringence typical of monosodium urate crystals (yellow when aligned parallel with the compensating filter, polarized light, 200x and 400x, respectively).

\section{Discussion}

A prevalent metabolic disorder of purine nucleotide degradation, gout is widely accepted as a peripheral joint disease [4]. Characteristically, gout results in arthritic pain as aggregates of monosodium urate crystals, or tophi, deposited in joints $[2,4,19]$. Up to approximately one-third of patients with chronic gout have tophaceous involvement of the spinal column $[1,2,4,8,26]$, with $80 \%$ of these lesions confined to the lumbar spine, followed by the thoracic spine $[1,4,8]$. Bonaldi et al. and Hou et al. have postulated that spinal inflammation as a result of motion-related degeneration provides an ideal environment for urate crystallization and deposition in the lumbar spine $[1,27]$.

While spinal gout is predominantly confined to the spinal epidural compartment $[1,4,19]$, there has been a paucity of reports on spinal intradural tophaceous gout: in 1987, Van der Laar et al. reported the first case of a cervical, intradural tophus causing compression [28]; in 2000, Paquette et al. described tophaceous gout of the filum terminale causing neural compression [29]; and in 2010, Ntisba et al illustrated an intradural thoracic tophus causing compression and myelopathy in a 43-year-old male with chronic gouty arthritis [30]. Because deposition of tophi in the spinal column can result in spinal stenosis/compression and mimic features of Pott's disease, osteomyelitis, discitis, epidural abscess, and metastatic disease $[9,12,31,32]$, Saketkoo et al. have argued for consideration of spinal gout in the differential diagnosis of all patients who present with pain and spinal compressive pathology in the context of gouty arthritis $[2,4]$.

Even though the majority of patients with spinal gout may manifest variable degrees of neurological compromise $[1,4,19]$, it is plausible for patients with gouty arthritis to enjoy long periods of quiescence provided that their uric acid levels are stringently controlled with optimal medical management [1]. Advances in pharmaceuticals have ushered in good clinical outcomes following pharmacologic treatment of spinal gout as highlighted by Chang [18]. Leventhal et al. demonstrated excellent neurological outcomes in patients with spinal gout who were treated conservatively [33]. Further, Ko et al. reported that poor control of systemic gout may accelerate the recurrence of spinal gout [34]. Regardless of etiology, progressive neurologic deterioration secondary to tophaceous compressive pathology requires surgical decompression to preserve neurological integrity. Improved diagnostic imaging capabilities (CT, MRI, and ultrasonography) have made image-guided needle biopsy of tophaceous lesions a possibility; however, surgery remains the gold standard because needle biopsies are associated with low sensitivity and poor diagnostic yield [1,35].

Systemic hyperuricemia results in uric acid deposition throughout the tissues in the body. Even though spinal gout is a known sequela of chronic gout, to our knowledge tophaceous gout involving the cavernous sinus and intradural spinal compartment in the same patient has not been described. A plausible explanation for this phenomenon may include the dissemination of gout through the intradural compartment and possibly the low permeability of the blood-brain-barrier (BBB) to uric acid crystals. Based on the initial diagnostic imaging characteristics (typical location, contrast enhancement, and dural tail), both the cranial and spinal lesions mimicked cavernous and spinal meningiomas, respectively. However, final pathologic diagnosis after craniotomy and laminectomy was consistent with gout as evidenced by the presence of uric acid crystals within the lesions. Although the patient did very well after his cranial procedure, he has yet to recover significantly from his spinal operation.

The pathophysiology of intracranial tophaceous gout, including intradural dissemination, remains poorly understood. Larger case series are required to elucidate the natural history of this unusual entity. 
Citation: Reinard KA, Felicella MM, Zakaria HM, Rock P (2015) Intradural Tophaceous Gout of the Cavernous Sinus and Spine: Case Report and Review of Literature. J Neurol Disord 3: 234. doi: 10.4172/2329-6895.1000234

Page 4 of 4

\section{References}

1. Hou LC, Hsu AR, Veeravagu A, Boakye M (2007) Spinal gout in a renal transplant patient: a case report and literature review. Surg Neurol 67: 65-73.

2. Lumezanu E, Konatalapalli R, Weinstein A (2012) Axial (spinal) gout. Curr Rheumatol Rep 14: 161-164.

3. Levin E, Hurth K, Joshi R, Brasington R (2011)Acute presentation of tophaceous myelopathy. J Rheumatol 38: 1525-1526.

4. Saketkoo LA, Robertson HJ, Dyer HR, Virk ZU, Ferreyro HR, et al. (2009) Axial gouty arthropathy. Am J Med Sci 338: 140-146.

5. Koskoff YD, Morris LE, Lubic LG (1953) Paraplegia as a complication of gout. J Am Med Assoc 152: 37-38.

6. Alarcón-Segovia DA, Cetina JA, Díaz-Jouanen E (1973) Sarcroilaic joints in primary gout. Clinical and roentgenographic study of 143 patients. Am J Roentgenol Radium Ther Nucl Med 118: 438-443.

7. Konatalapalli RM, Demarco PJ, Jelinek JS, Murphey M, Gibson M, et al. (2009) Gout in the axial skeleton. J Rheumatol 36: 609-613.

8. Konatalapalli RM, Lumezanu E, Jelinek JS, Murphey MD, Wang H, et al. (2012) Correlates of axial gout: a cross-sectional study. J Rheumatol 39: 1445-1449.

9. Barrett K, Miller ML, Wilson JT (2001) Tophaceous gout of the spine mimicking epidural infection: case report and review of the literature. Neurosurgery 48: 1170-1172.

10. Hausch R, Wilkerson M, Singh E, Reyes C, Harrington T (1999) Tophaceous gout of the thoracic spine presenting as back pain and fever. J Clin Rheumatol 5: 335-341.

11. Udayakumar D, Kteleh T, Alfata S, Bali T, Joseph A(2010) Spinal gout mimicking paraspinal abscess: A case report. J Radiol Case Rep 4: 15-20.

12. Yen PS, Lin JF, Chen SY, Lin SZ (2005) Tophaceous gout of the lumbar spine mimicking infectious spondylodiscitis and epidural abscess: MR imaging findings. J Clin Neurosci 12: 44-46.

13. Hsu CY, Shih TT, Huang KM, Chen PQ, Sheu JJ, et al. (2002) Tophaceous gout of the spine: MR imaging features. Clin Radiol 57: 919-925

14. Marinho F, Zeitoun-Eiss D, Renoux J, Brasseur JL, Genestie C, et al. (2012) Tophaceous gout of the spine: case report and review of the literature. J Neuroradiol 39: 123-126.

15. Dalbeth N, Doyle AJ (2012) Imaging of gout: an overview. Best Pract Res Clin Rheumatol 26: 823-838.

16. Nicolaou S, Yong-Hing CJ, Galea-Soler S, Hou DJ, Louis L, et al. (2010) Dualenergy CT as a potential new diagnostic tool in the management of gout in the acute setting. AJR Am J Roentgenol 194: 1072-1078.

17. McQueen FM, Doyle A, Dalbeth N (2011) Imaging in gout--what can we learn from MRI, CT, DECT and US? Arthritis Res Ther 13: 246.

18. Chang IC (2005) Surgical versus pharmacologic treatment of intraspinal gout. Clin Orthop Relat Res : 106-110.
19. Draganescu M, Leventhal LJ (2004) Spinal gout: case report and review of the literature. J Clin Rheumatol 10: 74-79.

20. Funck-Brentano T, Salliot C, Leboime A, Zafrani L, Servais A, et al. (2011) First observation of the efficacy of IL-1ra to treat tophaceous gout of the lumbar spine. Rheumatology (Oxford) 50: 622-624.

21. Vogl T, Ballhaus J, Dresel S, Kang K (1989) [Tophus of the base of the skull] Rofo 150: 613-614.

22. Saliba I, Bouthiller A, Desrochers P, Berthlet F, Dufour JJ (2003) Tophaceous gout and pseudogout of the middle ear and the infratemporal fossa: case report and review of the literature. J Otolaryngol 32: 269-272.

23. Reineke U, Ebmeyer J, Schütte F, Upile T, Sudhoff HH (2009) Tophaceous gout of the middle ear. Otol Neurotol 30: 127-128.

24. Tran A, Prentice D, Chan M (2011) Tophaceous gout of the odontoid process causing glossopharyngeal, vagus, and hypoglossal nerve palsies. Int J Rheum Dis 14: $105-108$

25. Vanpee G, Hermans G, Segers J, Gosselink R (2014) Assessment of limb muscle strength in critically ill patients: a systematic review. Crit Care Med 42 701-711.

26. De Mello FM, Helito PVP, Bordalo-Rodrigues M, Fuller R, Halpern ASR (2014) Axial gout is frequently associated with the presence of current tophi, although not with spinal symptoms. Spine 25: E1531-1536.

27. Bonaldi VM, Duong H, Starr MR, Sarazin L, Richardson J (1996) Tophaceous gout of the lumbar spine mimicking an epidural abscess: MR features. AJNR Am J Neuroradiol 17: 1949-1952.

28. van de Laar MA, van Soesbergen RM, Matricali B (1987) Tophaceous gout of the cervical spine without peripheral tophi. Arthritis Rheum 30: 237-238.

29. Paquette S, Lach B, Guiot B (2000) Lumbar radiculopathy secondary to gouty tophi in the filum terminale in a patient without systemic gout: case report. Neurosurgery 46: 986-988.

30. Ntsiba H, Makosso E, Moyikoua A (2010) Thoracic spinal cord compression by a tophus. Joint Bone Spine 77: 187-188.

31. Justiniano M, Colmegna I, Cuchacovich R, Espinoza LR (2007) Spondyloarthritis as a presentation of gouty arthritis. J Rheumatol 34: 1157-1158.

32. Suk KS, Kim KT, Lee SH, Park SW, Park YK (2007) Tophaceous gout of the lumbar spine mimicking pyogenic discitis. Spine J 7: 94-99.

33. Leventhal LJ, Levin RW, Bomalaski JS (1990) Peripheral arthrocentesis in the work-up of acute low back pain. Arch Phys Med Rehabil 71: 253-254.

34. Ko PJ, Huang TJ, Liao YS, Hsueh S, Hsu RW (1996) Recurrent spinal stenosis caused by tophaceous gout: a case report and review of literature. Changgeng Yi Xue Za Zhi 19: 272-276.

35. Pfister AK, Schlarb CA, O'Neal JF (1998) Vertebral erosion, paraplegia, and spinal gout. AJR Am J Roentgenol 171: 1430-1431. 